\title{
Streptococcus pneumoniae Otitis Media Pathogenesis and How It Informs Our Understanding of Vaccine Strategies
}

\author{
Caroline Bergenfelz ${ }^{1}$ - Anders P Hakansson ${ }^{1}$ \\ Published online: 20 May 2017 \\ (C) The Author(s) 2017. This article is an open access publication
}

\begin{abstract}
Purpose of Review This study aimed to review the literature regarding the mechanisms of transition from asymptomatic colonization to induction of otitis media and how the insight into the pathogenesis of otitis media has the potential to help design future otitis media-directed vaccines.

Recent Findings Respiratory viruses have long been shown to predispose individuals to bacterial respiratory infections, such as otitis media. Recent information suggests that Streptococcus pneumoniae, which colonize the nasopharynx asymptomatically, can sense potentially "threatening" changes in the nasopharyngeal environment caused by virus infection by upregulating specific sets of genes involved in biofilm release, dissemination from the nasopharynx to other sites, and protection against the host immune system. Furthermore, an understanding of the transcriptional and proteomic changes occurring in bacteria during transition to infection has led to identification of novel vaccine targets that are disease-specific and will not affect asymptomatic colonization. This approach will avoid major changes in the delicate balance of microorganisms in the respiratory tract microbiome due to elimination of $S$. pneumoniae. Summary Our recent findings are reviewed in the context of the current literature on the epidemiology and pathogenesis of otitis media. We also discuss how other otopathogens, such as Haemophilus influenzae and Moraxella catarrhalis, as well as the normal respiratory microbiome, can modulate the ability
\end{abstract}

This article is part of the Topical Collection on Pediatrics: Otitis Media in Children

Anders P Hakansson

anders_p.hakansson@med.lu.se

1 Division of Experimental Infection Medicine, Department of Translational Medicine, Wallenberg Laboratory, Lund University, Inga Marie Nilsson's Street 53, 20502 Malmö, SE, Sweden of pneumococci to cause infection. Furthermore, the unsatisfactory protection offered by the pneumococcal conjugate vaccines is highlighted and we review potential future strategies emerging to confer a more specific protection against otitis media.

Keywords Otitis media $\cdot$ Streptococcus pneumonia . Biofilm $\cdot$ Microbiome $\cdot$ Vaccine

\section{Otitis Media: Definitions and Complications}

Otitis media (OM) comprises a heterogeneous group of inflammatory disorders affecting the middle ear (ME). With over 700 million cases annually, $\mathrm{OM}$ is the most common reason for pediatric emergency room visits worldwide [1-3]. By the age of three, approximately $80 \%$ of all children have experienced at least one episode of OM, while a large percentage have had three or more, due to recurrent infection [4].

OM presents itself in several subtypes with acute or chronic elements that are classified based on symptoms (such as fever, irritability, pulling of the ear); visual appearance and/or perforation of the tympanic membrane; and presence of ME fluid, with and without active inflammation [5]. Acute otitis media $(\mathrm{AOM})$ generally affect children under the age of two and is characterized with sudden onset of symptoms, significant pain, and signs of inflammation with accumulation of purulent fluid behind the tympanic membrane. Based on new directives in several countries, including Sweden and parts of the USA, AOM in otherwise healthy children is usually treated with general analgesia, antipyretic drugs, and only for severe and recurrent cases with antibiotics. Despite this, OM is still a major reason for outpatient antibiotic prescription in the USA [2] and in many other parts of the world. 
In contrast, secretory otitis media (SOM, sometimes referred to as otitis media with effusion) is defined as a chronic inflammatory condition mainly affecting children between the age of 3 and 7. SOM may occur as a sequela to AOM and is generally not associated with any signs of an acute infection but presents with fluid behind the tympanic membrane and is associated with hearing impairment that over time can lead to cognitive and developmental problems $[6 \bullet \bullet, 7]$. The continuum of manifestations, ranging from uncomplicated, asymptomatic and self-limiting conditions to life-threatening, recurrent or chronic disorders with associated severe sequelae such as deafness, acute mastoiditis, or cholesteatoma are likely explained by the multifactorial and polymicrobial nature of OM [6••].

\section{The Microbiology of Otitis Media}

Respiratory viruses such as influenza viruses (A and B), rhinoviruses, respiratory syncytial virus (RSV), and adenoviruses are well-known causes of both asymptomatic and symptomatic OM $[8,9]$. Besides causing infection on their own, viruses commonly predisposes individuals to bacterial AOM that is generally more symptomatic and primarily caused by the bacterial triad Streptococcus pneumoniae (the pneumococcus), Haemophilus influenzae, and Moraxella catarrhalis [10]. A fourth pathogen worth mentioning is S. pyogenes, which although it only causes a small percentage of AOM cases, is the second most common organism associated with AOM complications [11]. The same bacterial species are also detected in ME fluid from patients with SOM, although an increased occurrence of bacteria such as Pseudomonas aeruginosa and $S$. aureus are detected in the ME fluid of these patients $[6 \bullet, 12-14]$. Whether this change in species tropism is indicative of a change in the ME environment, as the acute infection transitions into a more chronic state, or suggests that AOM and SOM are two separate clinical entities is currently not completely understood. Even though there are bacterial strains that are more otogenic, the bacteria associated with various subtypes of OM mostly reflect the composition of the normal nasopharyngeal microflora, and disease is associated with changes in the host environment that provides an opportunity for these organisms to actively move to the site of infection [15]. Among these bacterial organisms, S. pneumoniae and $H$. influenzae are the most common causes of OM overall, regardless of subtype.

S. pneumoniae, the focus of this review, accounts for 30 $50 \%$ of all AOM cases in different parts of the world, which amounts to approximately 300 million cases annually $[1,16 \bullet$, $17,18]$. S. pneumoniae is also an especially important pathogen in OM, as it is the main cause of recurrent infections as well as postinfectious complications, including ventilation tube insertion (myringostomy) [19••, 20••].

\section{Epidemiologic Correlations Between Colonization and Disease}

Although pneumococcal colonization is widespread, and mostly asymptomatic, transition to disease occurs frequently enough to make $S$. pneumoniae one of the main causes of respiratory tract infections, such as $\mathrm{OM}$, sinusitis, and pneumonia worldwide [3, 21-25].

\section{Bacterial Colonization and Otitis Media}

S. pneumoniae effectively colonize the mucosal surfaces of the nasopharynx (NP) beginning within the first few weeks or months of life [26••]. It is commonplace for children to be successively colonized and by the time they reach the age of two, greater than $95 \%$ of children will have been colonized with individual serotypes for weeks or months that are sequentially replaced as more serotypes are acquired [27-29]. The frequency and time of colonization in the NP has long been associated with increased risk of OM [30, 31] Furthermore, otitis-prone children are more heavily colonized than are non-otitis-prone children [10, 30, 32, 33], suggesting that the resident normal microflora participates in the pathogenesis of OM. Indeed, it is well established that colonization of the human NP always precedes the dissemination of bacteria to other sites, such as the ME, sinuses, lungs, as well as meninges and blood [3, 21, 34].

\section{Role of Viral-Bacterial Interactions in Induction of Pneumococcal Otitis Media}

Epidemiologically, transition from NP colonization to OM is highly correlated with concomitant viral infection $[8,35$, 36]. Indeed, many animal models of infection require or augment bacterial infection in the presence of a preceding viral infection [10, 37-39]. Essentially all upper respiratory tract viruses can predispose secondary bacterial OM, albeit with different propensities [10]. The mechanisms underlying this predisposition are in generally associated with suppression of the host immune response, although bacterial factors may play a partial role as well. Additionally, other changes to the host NP environment or co-colonization with other species of the respiratory tract microflora, such as the potential otopathogens $H$. influenzae and $M$. catarrhalis [30, 40-46], or the normal microflora are common and can modulate the pneumococcal transition from colonization to disease [26••, 47, $48 \bullet$ ] (see below for more detail). 


\section{Transition from Asymptomatic Biofilm Colonization to Otitis Media}

\section{Presence of Biofilms During Colonization and Disease}

It has been speculated over the years that pneumococci colonizing the NP may form biofilms [49-53], but it was not until recently that this was shown in mice in vivo $[54 \bullet \bullet, 55,56]$. Biofilms are collaborating multicellular communities closely associated with the mucosal epithelium and encased in a selfproduced polymeric matrix that often incorporates host components [57]. Aggregation in sessile biofilms provide the bacteria with a survival advantage in the harsh NP environment that is devoid of ample nutrition and where bacteria are exposed to factors of the innate immune response. [58-60]. As biofilms are inherently more resistant to antibacterial agents and able to resist host-immune responses, this will ultimately facilitate persistence and support the dissemination of virulent clones in the population.

Biofilms are present in up to $80 \%$ of all infections and are typically found in chronic and recurrent infections, such as OM [61]. Prior to our observation that asymptomatically colonizing pneumococci grow on the mucosal surface as biofilms $[54 \cdot \bullet, 55]$, in vivo biofilm formation had only been shown during disease states in association with adenoids and mucosal epithelium of children with recurrent or chronic ME disease and chronic rhinosinusitis $[62 \bullet \cdot, 63,64,65,66]$. However, it is unclear whether the biofilms detected at these disease sites represent asymptomatic colonization and persistence of bacteria from which virulent bacteria may seed off under the right conditions or if they are directly involved in the disease process $[50,53,67]$.

\section{Mechanisms of Transition to Otitis Media}

Biofilm bacteria grown in vitro have an avirulent phenotype and are unable to cause AOM in animals $[53,68,69 \bullet \cdot$. This is true also when bacterial biofilm colonization is induced in animals in vivo [69••]. However, virus infection is known to increase adherence of bacteria to epithelial cells [70-73], compromise the function of the Eustachian tube, induce dysfunction of the mucosal epithelium and immune cells [10], as well as to induce inflammation, fever, and the release of cytokines and other "danger signals" in the secretion [74-76]. All of these factors potentially contribute to the disruption of colonization and dissemination of bacteria.

Indeed, pneumococci are able to sense alterations in the NP environment resulting from virus infection [69••], including ATP and glucose release from damaged tissue, norepinephrine release from activation of a sympathomimetic response, and increased temperature associated with fever [77-80]. Each of these stimuli was shown to induce dispersal and dissemination of bacteria from asymptomatically colonized mice, resulting in severe AOM [69••, 81]. The increased virulence of biofilmdispersed bacteria in various animal infection models, including AOM, compared to planktonic, broth-grown bacteria, is explained by the major differences between the transcriptomes of the bacterial populations. Dispersed bacteria produced from an in vitro model system [82] exhibited major changes in their transcriptome with 134-1179 genes (depending on dispersal stimuli) being significantly up- or downregulated when compared to biofilm bacteria $[83 \bullet \bullet]$. Genes associated with carbohydrate metabolism, bacteriocin production, and common virulence factors such as capsule, $p s p A, p l y, p c p A$, nanA, and $n a n B$ were upregulated in dispersed bacteria, whereas competence genes and adhesins were downregulated [83••]. These results are supported by a proteomic study by Hall-Stoodley's laboratory, who showed that biofilm bacteria use alternative metabolic pathways and downregulate capsule and other virulence factors when compared to broth-grown bacteria [84••]. These results have provided a better understanding of the mechanisms involved in the induction of otitis media and have explained the increased virulence seen in animals infected with actively released biofilm bacteria compared to brothgrown bacteria.

\section{Modulation of Disease by the Respiratory Tract Microbiome}

Additionally, there is evidence that the normal microbiome is involved in modulating the transition from colonization to infection. In an elegant study by Bogaert and coworkers, children were followed for 12 months and the microbiome in the nasopharynx was analyzed and compared with the incidence of respiratory illnesses. In this study, bacterial species from the normal flora, such as Dolosogranulum spp., Corynebacterium spp., and Moraxella spp., were associated with less AOM, whereas Veillonella spp. and high levels of S. pneumoniae and $H$. influenzae were associated with a higher incidence of infection [26••]. The exact role of the interaction between S. pneumoniae and $H$. influenzae in vivo is not clear as studies have shown that non-typeable $H$. influenzae promoted pneumococcal biofilm formation in vitro [85], as well as in the chinchilla model of AOM, and reduced the incidence of systemic disease [67]. The effect on local infection is unclear.

Studies by Pettigrew and coworkers have, similarly, shown that Corynebacterium and Dolosigranulum are protective for development of OM, and that Actinomyces, Rothia, Neisseria, and Veillonella are associated with an increased risk for development of AOM [48••]. In contrast to Biesbroek et al., this study showed an association between Moraxella spp. and an increased colonization and risk for AOM with $S$. pneumoniae. This 
association is supported by studies showing that the presence of $M$. catarrhalis is a marker for increased severity of infection with other pathogens, including S. pneumoniae, and corresponding increases in the risk of AOM [86, 87]. Additionally, the ascension of pneumococci into the ME of mice was increased in the presence of M. catarrhalis in the nasopharynx, and $M$. catarrhalis was able to passively protect pneumococci against $\beta$-lactam killing in dual biofilms [88]. Still, the role of Moraxella spp. in disease induction could potentially differ with age as the ages of the study participants was lower in the Biesbroek study than in the Laufer study, and the protection against respiratory illnesses was especially pronounced at an early age. Based on this information, no clear picture of the role of the interaction between various species present in the nasopharynx and their role in protection or induction of AOM can be found.

\section{Vaccines}

\section{Effectiveness of Pneumococcal Conjugate Vaccines Against Otitis Media}

The poor immunogenicity of the 23-valent polysaccharide vaccine in infants and young children resulted in the development of the 7-valent pneumococcal conjugate vaccine Prevnar ${ }^{\circledR}$ (PCV7), released in 2000. This vaccine showed a strong immunogenicity in children [89]. Over the years, vaccines with increased valency have been developed to be more broadly protective and more suitable for the serotype distribution responsible for disease in other places than the USA. As of September 2016, conjugate vaccines, including Synflorix ${ }^{\circledR}$ (PHiD-CV or PCV10), a 10valent pneumococcal vaccine with $H$. influenzae protein $\mathrm{D}$, and PCV13 have, together with PCV7, been implemented in 132 countries around the world [90]. The vaccine efficacy has been most striking for invasive pneumococcal disease (IPD) with up to $93 \%$ protection detected [91••]. The effects of the pneumococcal conjugate vaccines (PVCs) against $\mathrm{OM}$ and its complications have unfortunately not provided similar levels of protection $[91 \bullet \bullet, 92,93 \bullet \bullet, 94,95]$.

Now, several years after the introduction of the PCV vaccines, it has become apparent that none of the vaccines have had a significant impact on nasopharyngeal colonization with S. pneumoniae [92, 93••, 96-98]. This is despite the $55-77 \%$ reduction in vaccine serotype-induced AOM compared to the prevaccine era $[16 \bullet \bullet, 91 \bullet \cdot]$ and the $35-46 \%$ reduction in all pneumococcal AOM $[91 \bullet \bullet, 99,100]$. This suggests that the vaccines have eliminated colonization with most vaccine serotypes but that serotype replacement with non-vaccine types has occurred rather immediately. However, these studies also indicate that the nonvaccine serotypes establishing colonization in the nasopharynx are, at least so far, less able to cause AOM. Interestingly, the allcause AOM is estimated to be reduced by only $0-7 \%$ in many regions of the world $[91 \bullet \bullet, 101,102]$, despite a reduction in pneumococcal OM, which suggest both that a concomitant increase in serotype replacement by non-vaccine serotypes is taking place to some extent and that AOM caused by other organisms is increasing. However, with the introduction of PCV13, some parts of the world with high levels of pneumococcal colonization and disease have seen a $24-68 \%$ reduction in all-cause AOM [16••, $103,104]$, suggesting an increased efficacy of the vaccine in areas with the highest disease burden. As not enough time has passed to make long-term predictions about the efficacy of these vaccines, continued monitoring of the nasopharyngeal microflora and causes of AOM will be important in the future in various parts of the world.

Although the total effect on pneumococcal AOM has not been as promising as for invasive disease, a major benefit with the current vaccines is that a $10-26 \%$ reduction in recurrent $\mathrm{AOM}$ and a $24-32 \%$ reduction in severe and complicated AOM, including a reduction of ventilation tube insertion, have been observed [19••, 105]. This is a positive result, albeit not completely surprising, as $S$. pneumoniae is most often associated with increased recurrence and severity of infection $[20 \bullet, 106]$.

\section{Future Vaccine Strategies}

Based on the incomplete protection against $S$. pneumoniaeinduced AOM conferred by the conjugate vaccines, and the fact that the evolutionary pressure and other causes will make the current vaccines less efficacious over time, several investigators have indicated that novel approaches, alone and in combination with current vaccine strategies, need to be implemented in the near future $[94,107 \bullet \bullet, 108]$. The fact that natural protection against pneumococcal colonization is dependent on antibodies to pneumococcal proteins, rather than capsular polysaccharide, suggests that an approach involving protein vaccine candidates may be most fruitful [109]. Whole-cell vaccines and protein vaccines with broad coverage across the over 95 serotypes are two approaches that have been suggested and investigated $[94,107 \bullet \bullet$. AOM-specific antigen targets have been identified in clinical studies of convalescent sera from AOM patients. Alpha-enolase, streptococcal lipoprotein rotamase A, putative proteinase maturation protein, histidine triad protein D, pneumolysin, pneumococcal surface adhesin A (PsaA), and pneumococcal surface protein A (PspA) are potential proteins that could be used for AOM-specific vaccine protection in the future [110-113].

Experiments with PspA have shown that the presence of anti-PspA antibodies in children reduces the risk of AOM [114]. Furthermore, mucosal immunization can protect mice against virus-induced AOM and reduces colonization burden of pneumococci $[115,116]$. In studies by Xu et al., PsaA was shown to protect mice from AOM [117]. Similarly, a study by Tuomanen and coworkers has shown that a fusion protein of pneumolysin and choline binding protein A (CbpA, PspC) protected against $\mathrm{OM}$ in mice [118]. It will be interesting to 
follow the development of these strategies as and if they progress towards finished vaccines.

\section{Potential Disease-Specific Vaccines Against AOM}

Each of the antigens mentioned above resulted in that the colonization burden was reduced concomitant to AOM protection. The advantage of eliminating pneumococcal colonization is that it will have a higher efficacy on the population as a whole, even with more targeted immunization policies, due to herd immunity. On the other hand, S. pneumoniae has evolved to become a harmless commensal organism in the nasopharyngeal microflora that inhibits the expansion of potentially more harmful organisms such as $S$. pyogenes and $S$. aureus through competitive exclusion $[119,120]$. The elimination of $S$. pneumoniae from this niche may therefore change the nasopharyngeal microbiome in a way that may or may not be detrimental in the future.

As an alternative, we have recently used the information gained from our studies regarding the transition from colonization to infection by choosing antigens that are conserved and highly upregulated on the surface of disease-causing organisms (i.e., the biofilm-dispersed pneumococci described above) [83]. In two studies, we have used either PspA [113] or eight antigens chosen for their upregulation in diseasecausing organisms [121] and immunized mice systemically rather than mucosally, to avoid effects on asymptomatic colonization. In both studies, we could protect mice from AOM with several antigens and against a panel of strains of different serotypes present and absent in the current vaccines, without affecting NP colonization $[113,121]$. This approach may provide one avenue towards disease-specific pneumococcal vaccines that avoid affecting the delicate balance between microorganisms in the nasopharynx.

\section{Concluding Remarks}

The fact that pneumococci grow as biofilms in the murine NP during asymptomatic carriage [54*0] has changed the way we consider both colonization and potential transition to infection. Bacteria within biofilms formed during NP colonization must balance attachment, growth, and eventual dispersion processes within a dynamic NP environment. Of these three critical steps, biofilm dispersal is by far the least understood. For S. pneumoniae, this is particularly troubling as biofilm dispersion represents the main step associated with clinical infections in susceptible patients: it is precisely these detached cells that are primed for dissemination to normally uninfected sites and are the causative agents of OM. Future studies are needed to better understand the exact mechanism of transition from asymptomatic colonization to infection and the molecules involved in pathogenesis in the disseminated and virulent population. Results from such studies have the potential to result in novel approaches to interfere with disease induction to prevent AOM and could be especially important for otitis-prone children.

The conjugate vaccines have had an enormous impact on IPD, for which the vaccines were designed, but have had a much lower efficacy against pneumonia and OM. The response to some of the serotypes, including $23 \mathrm{~F}$ and $6 \mathrm{~B}$, is known to be lower based on poorer immunogenicity [122], and vaccine escape is easily observable for the vaccineserotypes 19F, 23F, and 6B in AOM cases [101, 123, 124]. As new formulations of the conjugate vaccines have been introduced, it is becoming clearer that to provide better protection against $\mathrm{AOM}$ in the future, we will need to add to the current vaccine regimen using protein vaccines with broader and more AOM-specific activities. An understanding of the pathogenesis of AOM and the bacterial changes associated with virulence has great potential to provide clues to future effective vaccine targets.

Acknowledgements This work was supported by grants from the National Institutes of Health; the National Institute for Allergy and Infectious Diseases, USA; the Swedish Medical Research Council (VR), Österlunds Foundation, Lund, Sweden (APH); and the Royal Physiographic Society, Lund, Sweden and the Swedish Society for Medical Research (CB).

\section{Compliance with Ethical Standards}

Conflict of Interest Dr. Caroline Bergenfelz and Dr. Anders P. Hakansson declare that they have no conflict of interest.

Human and Animal Rights and Informed Consent This article does not contain any studies with human or animal subjects performed by any of the authors.

Open Access This article is distributed under the terms of the Creative Commons Attribution 4.0 International License (http:// creativecommons.org/licenses/by/4.0/), which permits unrestricted use, distribution, and reproduction in any medium, provided you give appropriate credit to the original author(s) and the source, provide a link to the Creative Commons license, and indicate if changes were made.

\section{References}

Papers of particular interest, published recently, have been highlighted as:

•- Of major importance

1. Monasta L, Ronfani L, Marchetti F, Montico M, Vecchi Brumatti L, Bavcar A, Grasso D, Barbiero C, Tamburlini G. Burden of disease caused by otitis media: systematic review and global estimates. PLoS One. 2012;7:e36226.

2. Froom J, Culpepper L, Jacobs M, DeMelker RA, Green LA, van Buchem L, Grob P, Heeren T. Antimicrobials for acute otitis media? A review from the International Primary Care Network. BMJ. 1997;315:98-102. 
3. Anonymous. Preventing pneumococcal disease among infants and young children. Recommendations of the advisory committee on immunization practices (ACIP). MMWR Morb Mortal Wkly Rep. 2000;49:1-35.

4. Teele DW, Klein JO, Rosner B. Epidemiology of otitis media during the first seven years of life in children in greater Boston: a prospective, cohort study. J Infect Dis. 1989;160:83-94.

5. Harkness P, Topham J. Classification of otitis media. Laryngoscope. 1998;108:1539-43.

6.• Qureishi A, Lee Y, Belfield K, Birchall JP, Daniel M. Update on otitis media - prevention and treatment. Infect Drug Resist. 2014;7:15-24. This is a recent, up-to-date review on the current state of otitis media with regard to pathogenesis, complications, treatment, and prevention.

7. Joint Committee on Infant Hearing. Year 2000 position statement: principles and guidelines for early hearing detection and intervention programs. Am J Audiol. 2000;9:9-29.

8. Henderson FW, Collier AM, Sanyal MA, Watkins JM, Fairclough DL, Clyde WA, Denny FW. A longitudinal study of respiratory viruses and bacteria in the etiology of acute otitis media with effusion. N Engl J Med. 1982;306:1377-83.

9. Heikkinen T, Ruuskanen O, Waris M, Ziegler T, Arola M, Halonen P. Influenza vaccination in the prevention of acute otitis media in children. Am J Dis Child. 1991;145:445-8.

10. Bakaletz LO. Immunopathogenesis of polymicrobial otitis media. J Leukoc Biol. 2010;87:213-22.

11. Kordeluk S, Kraus M, Leibovitz E. Challenges in the management of acute mastoiditis in children. Curr Infect Dis Rep. 2015;17:479.

12. Kubba H, Pearson JP, Birchall JP. The aetiology of otitis media with effusion: a review. Clin Otolaryngol Allied Sci. 2000;25:181-94.

13. Verhoeff M, van der Veen EL, Rovers MM, Sanders EA, Schilder AG. Chronic suppurative otitis media: a review. Int J Pediatr Otorhinolaryngol. 2006;70:1-12.

14. Prakash R, Juyal D, Negi V, Pal S, Adekhandi S, Sharma M, Sharma N. Microbiology of chronic suppurative otitis media in a tertiary care setup of uttarakhand state, India. N Am J Med Sci. 2013;5:282-7.

15. Zenni MK, Cheatham SH, Thompson JM, Reed GW, Batson AB, Palmer PS, Holland KL, Edwards KM. Streptococcus pneumoniae colonization in the young child: association with otitis media and resistance to penicillin. J Pediatr. 1995;127:533-7.

16.• Ben-Shimol S, Givon-Lavi N, Leibovitz E, Raiz S, Greenberg D, Dagan R. Impact of widespread introduction of pneumococcal conjugate vaccines on pneumococcal and nonpneumococcal otitis media. Clin Infect Dis. 2016;63:611-8. This is the first major study indicating that in areas with high incidence of otitis media, more recent conjugate vaccines with higher valency have shown a better protection against all-cause otitis media than in the rest of the world.

17. Block SL, Hedrick J, Harrison CJ, Tyler R, Smith A, Findlay R, Keegan E. Community-wide vaccination with the heptavalent pneumococcal conjugate significantly alters the microbiology of acute otitis media. Pediatr Infect Dis J. 2004;23:829-33.

18. Casey JR, Pichichero ME. Changes in frequency and pathogens causing acute otitis media in 1995-2003. Pediatr Infect Dis J. 2004;23:824-8

19.• Littorin N, Ahl J, Udden F, Resman F, Riesbeck K. Reduction of Streptococcus pneumoniae in upper respiratory tract cultures and a decreased incidence of related acute otitis media following introduction of childhood pneumococcal conjugate vaccines in a Swedish county. BMC Infect Dis. 2016;16:-407. A study that provides an excellent update on the reduced levels of complications from pneumococcal $\mathrm{AOM}$ after introduction of the PCV10 vaccine

20.• Van Dyke MK, Pirçon JY, Cohen R, Madhi SA, Rosenblüt A, Macias Parra M, Al-Mazrou K, Grevers G, Lopez P, Naranjo L, Pumarola F,
Sonsuwan N, Hausdorff WP. Etiology of acute otitis media in children less than 5 years of age: a pooled analysis of 10 similarly designed observational studies. Pediatr Infect Dis J. 2017;36:274-81. An excellent and recent compilation of studies investigating the etiologies of AOM after introduction of PCV7. The paper shows that $H$. influenzae is the most common bacterial agent causing AOM, followed by $S$. pneumoniae. The study also shows that $H$. influenzae was less likely to be isolated from the first incidence of AOM in any individual and also showed that $S$. pneumoniae was responsible for the majority of recurrent and more complicated AOM cases.

21. Heron MP, Smith BL. Deaths: leading causes for 2003. Natl Vital Stat Rep. 2007;55:1-92.

22. Sniadack DH, Schwartz B, Lipman H, Bogaerts J, Butler JC, Dagan R, Echaniz-Aviles G, Lloyd-Evans N, Fenoll A, Girgis NI, et al. Potential interventions for the prevention of childhood pneumonia: geographic and temporal differences in serotype and serogroup distribution of sterile site pneumococcal isolates from children-implications for vaccine strategies. Pediatr Infect Dis J. 1995;14:503-10.

23. O'Brien KL, Wolfson LJ, Watt JP, Henkle E, Deloria-Knoll M, McCall N, Lee E, Mulholland K, Levine OS, Cherian T. Burden of disease caused by Streptococcus pneumoniae in children younger than 5 years: global estimates. Lancet. 2009;374:893-902.

24. Klein JO. Otitis media. Clin Infect Dis. 1994;19:823-33.

25. Leowski J. Mortality from acute respiratory infections in children under 5 years of age: global estimates. World Health Stat Q. 1986;39:138-44.

26.• Biesbroek G, Tsivtsivadze E, Sanders EA, Montijn R, Veenhoven RH, Keijser BJ, Bogaert D. Early respiratory microbiota composition determines bacterial succession patterns and respiratory health in children. Am J Respir Crit Care Med. 2014;190:128392. This study together with reference 48 highlights new information regarding the important influence of the respiratory tract microbiome in modulating respiratory illnesses. In this study, children were followed during their first year of life and their microbiomes were determined. The species found in the microbiome could be correlated with the risk of respiratory illnesses. The study showed that species such as Dolosogranulum and Corynebacteria were found predominantly in children with less frequency of infection.

27. Bogaert D, De Groot R, Hermans PW. Streptococcus pneumoniae colonisation: the key to pneumococcal disease. Lancet Infect Dis. 2004;4:144-54.

28. Gray BM, Converse GM, Dillon HC. Epidemiologic studies of Streptococcus pneumoniae in infants: acquisition, carriage, and infection during the first 24 months of life. J Infect Dis. 1980;142:923-33.

29. Huebner RE, Dagan R, Porath N, Wasas AD, Klugman KP. Lack of utility of serotyping multiple colonies for detection of simultaneous nasopharyngeal carriage of different pneumococcal serotypes. Pediatr Infect Dis J. 2000;19:1017-20.

30. Garcia-Rodriguez JA, Fresnadillo Martinez MJ. Dynamics of nasopharyngeal colonization by potential respiratory pathogens. J Antimicrob Chemother. 2002;50(Suppl S2):59-73.

31. Faden H, Duffy L, Wasielewski R, Wolf J, Krystofik D, Tung Y. Relationship between nasopharyngeal colonization and the development of otitis media in children Tonawanda/Williamsville Pediatrics. J Infect Dis. 1997;175:1440-5.

32. Torretta S, Marchisio P, Drago L, Baggi E, De Vecchi E, Garavello W, Nazzari E, Pignataro L, Esposito S. Nasopharyngeal biofilmproducing otopathogens in children with nonsevere recurrent acute otitis media. Otolaryngol Head Neck Surg. 2012;146:991-6.

33. Xu Q, Casey JR, Newman E, Pichichero ME. Otitis-prone children have immunologic deficiencies in naturally acquired 
nasopharyngeal mucosal antibody response after Streptococcus pneumoniae colonization. Pediatr Infect Dis J. 2016;35:54-60.

34. Kadioglu A, Weiser JN, Paton JC, Andrew PW. The role of Streptococcus pneumoniae virulence factors in host respiratory colonization and disease. Nat Rev Microbiol. 2008;6:288-301.

35. Chonmaitree T, Howie VM, Truant AL. Presence of respiratory viruses in middle ear fluids and nasal wash specimens from children with acute otitis media. Pediatrics. 1986;77:698-702.

36. Pettigrew MM, Gent JF, Pyles RB, Miller AL, Nokso-Koivisto J, Chonmaitree T. Viral-bacterial interactions and risk of acute otitis media complicating upper respiratory tract infection. J Clin Microbiol. 2011;49:3750-5.

37. Tong HH, Weiser JN, James MA, DeMaria TF. Effect of influenza a virus infection on nasopharyngeal colonization and otitis media induced by transparent or opaque phenotype variants of Streptococcus pneumoniae in the chinchilla model. Infect Immun. 2001;69:602-6.

38. Giebink GS, Dee TH, Kim Y, Quie PG. Alterations in serum opsonic activity and complement levels in pneumococcal disease. Infect Immun. 1980;29:1062-6.

39. Bakaletz LO, Daniels RL, Lim DJ. Modeling adenovirus type 1induced otitis media in the chinchilla: effect on ciliary activity and fluid transport function of eustachian tube mucosal epithelium. J Infect Dis. 1993;168:865-72.

40. Weiser JN. The pneumococcus: why a commensal misbehaves. J Mol Med (Berl). 2010;88:97-102.

41. Rivera-Olivero IA, Blommaart M, Bogaert D, Hermans PW, de Waard JH. Multiplex PCR reveals a high rate of nasopharyngeal pneumococcal 7 -valent conjugate vaccine serotypes co-colonizing indigenous Warao children in Venezuela. J Med Microbiol. 2009;58:584-7.

42. O'Brien KL, Millar EV, Zell ER, Bronsdon M, Weatherholtz R, Reid R, Becenti J, Kvamme S, Whitney CG, Santosham M. Effect of pneumococcal conjugate vaccine on nasopharyngeal colonization among immunized and unimmunized children in a community-randomized trial. J Infect Dis. 2007;196:1211-20.

43. Auranen K, Mehtala J, Tanskanen A, S Kaltoft M. Between-strain competition in acquisition and clearance of pneumococcal carriage - epidemiologic evidence from a longitudinal study of daycare children. Am J Epidemiol. 2010;171:169-76.

44. Long SS, Henretig FM, Teter MJ, McGowan KL. Nasopharyngeal flora and acute otitis media. Infect Immun. 1983;41:987-91.

45. Murphy TF, Bakaletz LO, Smeesters PR. Microbial interactions in the respiratory tract. Pediatr Infect Dis J. 2009;28:S121-6.

46. Xu Q, Casey JR, Chang A, Pichichero ME. When co-colonizing the nasopharynx Haemophilus influenzae predominates over Streptococcus pneumoniae except serotype 19A strains to cause acute otitis media. Pediatr Infect Dis J. 2012;31:638-40.

47. Pettigrew MM, Gent JF, Revai K, Patel JA, Chonmaitree T. Microbial interactions during upper respiratory tract infections. Emerg Infect Dis. 2008;14:1584-91.

48.• Laufer AS, Metlay JP, Gent JF, Fennie KP, Kong Y, Pettigrew MM. Microbial communities of the upper respiratory tract and otitis media in children. MBio. 2011;2:e00245-10. In this elegant study, the authors pinpoint the importance of the normal respiratory tract microflora in predicting the risk of AOM. Children with Dolosogranulum and Corynebacteria in their microflora were found to be protected against $\mathrm{AOM}$, and children carrying Rothia, Veillonella, and Moraxella spp. were found to have higher incidence of AOM.

49. Munoz-Elias EJ, Marcano J, Camilli A. Isolation of Streptococcus pneumoniae biofilm mutants and their characterization during nasopharyngeal colonization. Infect Immun. 2008;76:5049-61.

50. Oggioni MR, Trappetti C, Kadioglu A, Cassone M, Iannelli F, Ricci S, Andrew PW, Pozzi G. Switch from planktonic to sessile life: a major event in pneumococcal pathogenesis. Mol Microbiol. 2006;61:1196-210.

51. Waite RD, Struthers JK, Dowson CG. Spontaneous sequence duplication within an open reading frame of the pneumococcal type 3 capsule locus causes high-frequency phase variation. Mol Microbiol. 2001;42:1223-32.

52. Trappetti C, Kadioglu A, Carter M, Hayre J, Iannelli F, Pozzi G, Andrew PW, Oggioni MR. Sialic acid: a preventable signal for pneumococcal biofilm formation, colonization, and invasion of the host. J Infect Dis. 2009;199:1497-505.

53. Sanchez CJ, Kumar N, Lizcano A, Shivshankar P, Dunning Hotopp JC, Jorgensen JH, Tettelin H, Orihuela CJ. Streptococcus pneumoniae in biofilms are unable to cause invasive disease due to altered virulence determinant production. PLoS One. 2011;6:e28738.

54.• Marks LR, Parameswaran GI, Hakansson AP. Pneumococcal interactions with epithelial cells are crucial for optimal biofilm formation and colonization in vitro and in vivo. Infect Immun. 2012;80:2744-60. This is the first paper to show that pneumococcal biofilms are formed during nasopharyngeal colonization in vivo and that the in vitro biofilm-forming ability of pneumococcal strains on epithelial cells rather than on abiotic surfaces correlates better with the ability of the same stains to colonize mice in vivo.

55. Marks LR, Reddinger RM, Hakansson AP. High levels of genetic recombination during nasopharyngeal carriage and biofilm formation in Streptococcus pneumoniae. MBio. 2012;3:e0200-12.

56. Blanchette-Cain K, Hinojosa CA, Akula Suresh Babu R, Lizcano A, Gonzalez-Juarbe N, Munoz-Almagro C, Sanchez CJ, Bergman MA, Orihuela CJ. Streptococcus pneumoniae biofilm formation is strain dependent, multifactorial, and associated with reduced invasiveness and immunoreactivity during colonization. MBio. 2013;4:e0745-13.

57. Stoodley P, Sauer K, Davies DG, Costerton JW. Biofilms as complex differentiated communities. Annu Rev Microbiol. 2002;56: 187-209.

58. Lewis K. Multidrug tolerance of biofilms and persister cells. Curr Top Microbiol Immunol. 2008;322:107-31.

59. Chole RA, Faddis BT. Anatomical evidence of microbial biofilms in tonsillar tissues: a possible mechanism to explain chronicity. Arch Otolaryngol Head Neck Surg. 2003;129:634-6.

60. Donlan RM, Costerton JW. Biofilms: survival mechanisms of clinically relevant microorganisms. Clin Microbiol Rev. 2002:15:167-93.

61. Wolcott RD, Ehrlich GD. Biofilms and chronic infections. JAMA. 2008;299:2682-4.

62.• Reid SD, Hong W, Dew KE, Winn DR, Pang B, Watt J, Glover DT, Hollingshead SK, Swords WE. Streptococcus pneumoniae forms surface-attached communities in the middle ear of experimentally infected chinchillas. J Infect Dis. 2009;199:786-94. Biofilms have been observed in children with otitis media and have been thought to contribute or be directly involved in pneumococcal AOM. However, in this landmark paper, the authors convincingly propose, similar to reference 53 and 54 , that biofilm bacteria are non-virulent but that biofilms can be thought of as a virulence property based on being a reservoir for pathogenic bacteria.

63. Hall-Stoodley L, Hu FZ, Gieseke A, Nistico L, Nguyen D, Hayes J, Forbes M, Greenberg DP, Dice B, Burrows A, Wackym PA, Stoodley P, Post JC, Ehrlich GD, Kerschner JE. Direct detection of bacterial biofilms on the middle-ear mucosa of children with chronic otitis media. JAMA. 2006;296:202-11.

64. Sanderson AR, Leid JG, Hunsaker D. Bacterial biofilms on the sinus mucosa of human subjects with chronic rhinosinusitis. Laryngoscope. 2006;116:1121-6. 
65. Hoa M, Syamal M, Sachdeva L, Berk R, Coticchia J. Demonstration of nasopharyngeal and middle ear mucosal biofilms in an animal model of acute otitis media. Ann Otol Rhinol Laryngol. 2009;118:292-8.

66. Sanchez CJ, Shivshankar P, Stol K, Trakhtenbroit S, Sullam PM, Sauer K, Hermans PW, Orihuela CJ. The pneumococcal serinerich repeat protein is an intra-species bacterial adhesin that promotes bacterial aggregation in vivo and in biofilms. PLoS Pathog. 2010;6:e1001044.

67. Weimer KE, Armbruster CE, Juneau RA, Hong W, Pang B, Swords WE. Coinfection with Haemophilus influenzae promotes pneumococcal biofilm formation during experimental otitis media and impedes the progression of pneumococcal disease. J Infect Dis. 2010;202:1068-75.

68. Gilley RP, González-Juarbe N, Shenoy AT, Reyes LF, Dube PH, Restrepo MI, Orihuela CJ. Infiltrated macrophages die of pneumolysin-mediated necroptosis following pneumococcal myocardial invasion. Infect Immun. 2016;84:1457-69.

69.• Marks LR, Davidson BA, Knight PR, Hakansson AP. Interkingdom signaling induces Streptococcus pneumoniae biofilm dispersion and transition from asymptomatic colonization to disease. MBio. 2013;4:e00438-13. In this paper, the authors provide mechanistic information regarding the transition from colonization to otitis media and pneumonia. The study shows that viral infection or molecules associated with stress and inflammation are sensed by colonizing pneumococcal biofilms and result in bacterial release from biofilms and dissemination to the middle ear and lung, where they cause inflammatory disease.

70. Hakansson A, Kidd A, Wadell G, Sabharwal H, Svanborg C. Adenovirus infection enhances in vitro adherence of Streptococcus pneumoniae. Infect Immun. 1994;62:2707-14.

71. McCullers JA. Insights into the interaction between influenza virus and pneumococcus. Clin Microbiol Rev. 2006;19:571-82.

72. Avadhanula V, Rodriguez CA, Devincenzo JP, Wang Y, Webby RJ, Ulett GC, Adderson EE. Respiratory viruses augment the adhesion of bacterial pathogens to respiratory epithelium in a viral species- and cell type-dependent manner. J Virol. 2006;80:1629-36.

73. El Ahmer OR, Raza MW, Ogilvie MM, Weir DM, Blackwell CC. Binding of bacteria to HEp-2 cells infected with influenza A virus. FEMS Immunol Med Microbiol. 1999;23:331-41.

74. Dunn AJ, Powell ML, Meitin C, Small PAJ. Virus infection as a stressor: influenza virus elevates plasma concentrations of corticosterone, and brain concentrations of MHPG and tryptophan. Physiol Behav. 1989:45:591-4.

75. Pacheco AR, Sperandio V. Inter-kingdom signaling: chemical language between bacteria and host. Curr Opin Microbiol. 2009;12: 192-8.

76. Riteau N, Gasse P, Fauconnier L, Gombault A, Couegnat M, Fick L, Kanellopoulos J, Quesniaux VF, Marchand-Adam S, Crestani B, Ryffel B, Couillin I. Extracellular ATP is a danger signal activating $\mathrm{P} 2 \mathrm{X} 7$ receptor in lung inflammation and fibrosis. Am $\mathrm{J}$ Respir Crit Care Med. 2010;182:774-83.

77. Button B, Picher M, Boucher RC. Differential effects of cyclic and constant stress on ATP release and mucociliary transport by human airway epithelia. J Physiol. 2007;580:577-92.

78. Ferrari D, Chiozzi P, Falzoni S, Hanau S, Di Virgilio F. Purinergic modulation of interleukin-1 beta release from microglial cells stimulated with bacterial endotoxin. J Exp Med. 1997;185:579-82.

79. Takenouchi T, Sugama S, Iwamaru Y, Hashimoto M, Kitani H. Modulation of the ATP-lnduced release and processing of IL1beta in microglial cells. Crit Rev Immunol. 2009;29:335-45.

80. Schwiebert EM, Zsembery A. Extracellular ATP as a signaling molecule for epithelial cells. Biochim Biophys Acta. 2003;1615:7-32.

81. Chao Y, Marks LR, Pettigrew MM, Hakansson AP. Streptococcus pneumoniae biofilm formation and dispersion during colonization and disease. Front Cell Infect Microbiol. 2015;4:194. 1-16
82. Chao Y, Bergenfelz C, Hakansson AP (2017) In vitro and in vivo biofilm formation by pathogenic Streptococci. In: Nordenfelt P, Collin M (eds) Methods Mol Biol. 2017; 1535: 285-299.

83.• Pettigrew MM, Marks LR, Kong Y, Gent JF, Roche-Hakansson H, Hakansson AP. Dynamic changes in the Streptococcus pneumoniae transcriptome during transition from biofilm formation to invasive disease upon influenza A virus infection. Infect Immun. 2014;82: $4607-19$. This study shows that biofilm bacteria and bacteria that cause infection and disease of the middle ear express very different genes associated with quiet colonization and protection from host inflammation and the competitive microflora, respectively.

84.•• Allan RN, Skipp P, Jefferies J, Clarke SC, Faust SN, Hall-Stoodley L, Webb J. Pronounced metabolic changes in adaptation to biofilm growth by Streptococcus pneumoniae. PLoS One. 2014;9:e107015. In this study, the authors show similar results as in reference 83 but on a proteomic level. The authors show elegantly that biofilm bacteria and broth-grown bacteria express very different proteins associated with metabolism and virulence.

85. Hong W, Khampang P, Erbe C, Kumar S, Taylor SR, Kerschner JE. Nontypeable Haemophilus influenzae inhibits autolysis and fratricide of Streptococcus pneumoniae in vitro. Microbes Infect. 2014;16:203-13.

86. Ruohola A, Meurman O, Nikkari S, Skottman T, Salmi A, Waris M, Osterback R, Eerola E, Allander T, Niesters H, Heikkinen T, Ruuskanen O. Microbiology of acute otitis media in children with tympanostomy tubes: prevalences of bacteria and viruses. Clin Infect Dis. 2006;43:1417-22.

87. Ruohola A, Pettigrew MM, Lindholm L, Jalava J, Raisanen KS, Vainionpaa R, Waris M, Tahtinen PA, Laine MK, Lahti E, Ruuskanen O, Huovinen P. Bacterial and viral interactions within the nasopharynx contribute to the risk of acute otitis media. J Inf Secur. 2013;66:247-54.

88. Perez AC, Pang B, King LB, Tan L, Murrah KA, Reimche JL, Wren JT, Richardson SH, Ghandi U, Swords WE. Residence of Streptococcus pneumoniae and Moraxella catarrhalis within polymicrobial biofilm promotes antibiotic resistance and bacterial persistence in vivo. Pathog Dis. 2014;70:280-8.

89. Menon VJ, Corscadden KJ, Fuery A, Thornton RB, Kirkham LA, Richmond PC, Wiertsema SP. Children with otitis media mount a pneumococcal serotype specific serum IgG and IgA response comparable to healthy controls after pneumococcal conjugate vaccination. Vaccine. 2012;30:3136-44.

90. Loharikar A, Dumolard L, Chu S, Hyde T, Goodman T, Mantel C. Status of new vaccine introduction-worldwide, September 2016. MMWR Morb Mortal Wkly Rep. 2016;65:1136-40.

91.• WHO. Pneumococcal vaccines WHO position paper. Wkly Epidemiol Rec. 2012;87:129-44. This position paper from the World Health Organization summarizes the role of the conjugate vaccines on pneumococcal AOM and other pneumococcal diseases.

92. WHO. Pneumococcal conjugate vaccine for childhood immunization-WHO position paper. Wkly Epidemiol Rec. 2007;82:93-104.

93.•- Fortanier AC, Venekamp RP, Boonacker CW, Hak E, Schilder AG, Sanders EA, Damoiseaux RA. Pneumococcal conjugate vaccines for preventing otitis media. Cochrane Database Syst Rev. 2014;(4):CD001480. An excellent compilation of the studies up until 2014 on the effect of the more recent conjugate vaccines, PCV10 and PCV13, on prevention of AOM. The study shows a serotype-specific protection, with an increase of AOM caused by non-vaccine serotypes. It also shows that despite a decrease in all-pneumococcal AOM, the all-cause AOM remains unaffected, suggesting that other organisms replace pneumococci as pathogens in AOM.

94. Moffitt KL, Malley R. Next generation pneumococcal vaccines. Curr Opin Immunol. 2011;23:407-13. 
95. Daniels CC, Rogers PD, Shelton CM. A review of pneumococcal vaccines: current polysaccharide vaccine recommendations and future protein antigens. J Pediatr Pharmacol Ther. 2016;21:27-35.

96. Dagan R, Juergens C, Trammel J, Patterson S, Greenberg D, Givon-Lavi N, Porat N, Gurtman A, Gruber WC, Scott DA. Efficacy of 13-valent pneumococcal conjugate vaccine (PCV13) versus that of 7-valent PCV (PCV7) against nasopharyngeal colonization of antibiotic-nonsusceptible Streptococcus pneumoniae. J Infect Dis. 2015;211:1144-53.

97. van den Bergh MR, Spijkerman J, Swinnen KM, François NA, Pascal TG, Borys D, Schuerman L, Ijzerman EP, Bruin JP, van der Ende A, Veenhoven RH, Sanders EA. Effects of the 10-valent pneumococcal nontypeable Haemophilus influenzae protein D-conjugate vaccine on nasopharyngeal bacterial colonization in young children: a randomized controlled trial. Clin Infect Dis. 2013;56:e30-9.

98. Angoulvant F, Cohen R, Doit C, Elbez A, Werner A, Béchet S, Bonacorsi S, Varon E, Levy C. Trends in antibiotic resistance of Streptococcus pneumoniae and Haemophilus influenzae isolated from nasopharyngeal flora in children with acute otitis media in France before and after 13 valent pneumococcal conjugate vaccine introduction. BMC Infect Dis. 2015;15:236.

99. Hays C, Vermee Q, Agathine A, Dupuis A, Varon E, Poyart C, Ploy MC, Raymond J. Demonstration of the herd effect in adults after the implementation of pneumococcal vaccination with PCV13 in children. Eur J Clin Microbiol Infect Dis 2016.

100. Delgleize E, Leeuwenkamp O, Theodorou E, Van de Velde N. Cost-effectiveness analysis of routine pneumococcal vaccination in the UK: a comparison of the PHiD-CV vaccine and the PCV-13 vaccine using a Markov model. BMJ Open. 2016;6:e10776.

101. Vesikari T, Forsten A, Seppä I, Kaijalainen T, Puumalainen T, Soininen A, Traskine M, Lommel P, Schoonbroodt S, Hezareh M, Moreira M, Borys D, Schuerman L. Effectiveness of the 10valent pneumococcal nontypeable Haemophilus influenzae protein D-conjugated vaccine (PHiD-CV) against carriage and acute otitis media-a double-blind randomized clinical trial in Finland. J Pediatric Infect Dis Soc. 2016;5:237-48.

102. Ewald H, Briel M, Vuichard D, Kreutle V, Zhydkov A, Gloy V. The clinical effectiveness of pneumococcal conjugate vaccines: a systematic review and meta-analysis of randomized controlled trials. Dtsch Arztebl Int. 2016;113:139-46.

103. Sigurdsson S, Kristinsson KG, Erlendsdóttir H, Hrafnkelsson B, Haraldsson Á. Decreased incidence of respiratory infections in children after vaccination with ten-valent pneumococcal vaccine. Pediatr Infect Dis J. 2015;34:1385-90.

104. Prymula R, Peeters P, Chrobok V, Kriz P, Novakova E, Kaliskova E, Kohl I, Lommel P, Poolman J, Prieels JP, Schuerman L. Pneumococcal capsular polysaccharides conjugated to protein D for prevention of acute otitis media caused by both Streptococcus pneumoniae and non-typable Haemophilus influenzae: a randomised double-blind efficacy study. Lancet. 2006;367:740-8.

105. Fireman B, Black SB, Shinefield HR, Lee J, Lewis E, Ray P. Impact of the pneumococcal conjugate vaccine on otitis media. Pediatr Infect Dis J. 2003;22:10-6.

106. Ovnat Tamir S, Roth Y, Goldfarb A, Grotto I, Marom T. Severity of pneumococcal versus non-pneumococcal acute otitis media in children. Clin Otolaryngol. 2015;40:370-7.

107.• Rodgers GL, Klugman KP. The future of pneumococcal disease prevention. Vaccine. 2011;29(Suppl 3):C43-8. This seminal opinion paper concludes that pneumococcal conjugate vaccines will not be able to eliminate pneumococcal AOM or pneumococcal disease. For that to occur, other strategies are needed, most likely including protein vaccines with broad protection.

108. Klugman KP. Contribution of vaccines to our understanding of pneumococcal disease. Philos Trans R Soc Lond Ser B Biol Sci. 2011;366:2790-8.
109. Wilson R, Cohen JM, Reglinski M, Jose RJ, Chan WY, Marshall H, de Vogel C, Gordon S, Goldblatt D, Petersen FC, Baxendale H, Brown JS. Naturally acquired human immunity to pneumococcus is dependent on antibody to protein antigens. PLoS Pathog. 2017;13:e1006137.

110. Adrian PV, Bogaert D, Oprins M, Rapola S, Lahdenkari M, Kilpi T, de Groot R, Käyhty H, Hermans PW. Development of antibodies against pneumococcal proteins alpha-enolase, immunoglobulin A1 protease, streptococcal lipoprotein rotamase A, and putative proteinase maturation protein $\mathrm{A}$ in relation to pneumococcal carriage and otitis media. Vaccine. 2004;22:2737-42.

111. Pichichero ME, Casey JR, Almudevar A. Nonprotective responses to pediatric vaccines occur in children who are otitis prone. Pediatr Infect Dis J. 2013;32:1163-8.

112. Xu Q, Casey JR, Almudevar A, Pichichero ME. Correlation of higher antibody levels to pneumococcal proteins with protection from pneumococcal acute otitis media but not protection from nasopharyngeal colonization in young children. Clin Microbiol Infect 2017 (published ahead of print January 28).

113. Greene CJ, Marks LR, Hu JC, Reddinger R, Mandell L, RocheHakansson H, King-Lyons ND, Connell TD, Hakansson AP. Novel strategy to protect against influenza virus-induced pneumococcal disease without interfering with commensal colonization. Infect Immun. 2016;84:1693-703.

114. Simell B, Melin M, Lahdenkari M, Briles DE, Hollingshead SK, Kilpi TM, Kayhty H. Antibodies to pneumococcal surface protein A families 1 and 2 in serum and saliva of children and the risk of pneumococcal acute otitis media. J Infect Dis. 2007;196:1528-36.

115. Habets MN, van Selm S, van Opzeeland FJ, Simonetti E, Hermans PW, de Jonge MI, Diavatopoulos DA. Role of antibodies and IL17-mediated immunity in protection against pneumococcal otitis media. Vaccine. 2016;34:5968-74.

116. Briles DE, Hollingshead SK, Nabors GS, Paton JC, Brooks-Walter A. The potential for using protein vaccines to protect against otitis media caused by Streptococcus pneumoniae. Vaccine. 2000;19(Suppl 1):S87-95.

117. Xu JH, Dai WJ, Chen B, Fan XY. Mucosal immunization with PsaA protein, using chitosan as a delivery system, increases protection against acute otitis media and invasive infection by Streptococcus pneumoniae. Scand J Immunol. 2015;81:177-85.

118. Mann B, Thornton J, Heath R, Wade KR, Tweten RK, Gao G, El Kasmi K, Jordan JB, Mitrea DM, Kriwacki R, Maisonneuve J, Alderson M, Tuomanen EI. Broadly protective protein-based pneumococcal vaccine composed of pneumolysin toxoid-CbpA peptide recombinant fusion protein. J Infect Dis 2013.

119. Lewnard JA, Huppert A, Givon-Lavi N, Pettigrew MM, RegevYochay G, Dagan R, Weinberger DM. Density, serotype diversity, and fitness of Streptococcus pneumoniae in upper respiratory tract co-colonization with nontypeable Haemophilus influenzae. J Infect Dis. 2016;214:1411-20.

120. Biesbroek G, Wang X, Keijser BJ, Eijkemans RM, Trzcinski K, Rots NY, Veenhoven RH, Sanders EA, Bogaert D. Seven-valent pneumococcal conjugate vaccine and nasopharyngeal microbiota in healthy children. Emerg Infect Dis. 2014;20:201-10.

121. Li Y, Hill A, Beitelshees M, Shao S, Lovell JF, Davidson BA, Knight PR, Hakansson AP, Pfeifer BA, Jones CH. Directed vaccination against pneumococcal disease. Proc Natl Acad Sci U S A. 2016;111:12360-5.

122. Black S, Shinefield H, Fireman B, Lewis E, Ray P, Hansen JR, Elvin L, Ensor KM, Hackell J, Siber G, Malinoski F, Madore D, Chang I, Kohberger R, Watson W, Austrian R, Edwards K. Efficacy, safety and immunogenicity of heptavalent pneumococcal conjugate vaccine in children. Northern California Kaiser Permanente vaccine study center group. Pediatr Infect Dis J. 2000;19:187-95.

123. Leach AJ, Wigger C, Beissbarth J, Woltring D, Andrews R, Chatfield MD, Smith-Vaughan H, Morris PS. General health, otitis media, nasopharyngeal carriage and middle ear microbiology 
in northern territory aboriginal children vaccinated during consecutive periods of 10-valent or 13-valent pneumococcal conjugate vaccines. Int J Pediatr Otorhinolaryngol. 2016;86:224-32.

124. Marchisio P, Esposito S, Picca M, Baggi E, Terranova L, Orenti A, Biganzoli E, Principi N, Milan AOMSG. Serotypes not included in 13-valent pneumococcal vaccine as causes of acute otitis media with spontaneous tympanic membrane perforation in a geographic area with high vaccination coverage. Pediatr Infect Dis J 2016 (Published ahead of print December 15). 